Hyperpolarizing and depolarizing square steps were imposed on the membrane potential of excised human intercostal muscle fibers by means of a 3-microelectrode voltage clamp. The steady-state amplitudes of the membrane currents inducing such steps were investigated as a function of the membrane potential, while the muscle was bathed in solutions varying in potassium content $\left(K_{e}=1,3.5,7,20\right.$, and $60 \mathrm{mM}$ ). At all potassium concentrations, the membrane acted as a rectifier, both in the inward-and outward-going directions. Inward currents were much reduced when $\mathrm{K}_{e}$ was lowered from 3.5 to $1 \mathrm{mM}$, and were increased when $\mathrm{K}_{\mathrm{e}}$ was raised beyond $3.5 \mathrm{mM}$. The delayed outward current was reduced when $\mathrm{K}_{e}$ was increased from $3.5 \mathrm{mM}$ to $7 \mathrm{mM}$ and higher potassium concentration. The results were qualitatively similar to those reported for rat skeletal muscle.

MUSCLE \& NERVE $\quad 7: 465-469 \quad 1984$

\title{
MEMBRANE CURRENTS IN HUMAN INTERCOSTAL MUSCLE AT VARIED EXTRACELLULAR POTASSIUM
}

\author{
HUBERT KWIECIŃSKI, MD, FRANK LEHMANN-HORN, MD, \\ and REINHARDT RÜDEL, PhD
}

The ionic conductivity of the skeletal muscle fiber membrane can best be studied by the voltage clamp technique. The currents needed to displace the membrane potential from its resting value to a new steady level show a peculiar nonlinear dependence on the imposed membrane potential: the membrane acts as a rectifier both in the inwardand outward-going directions. Such nonlinear membrane characteristics have been found in frog muscle, ${ }^{1}$ and also in rat muscle. ${ }^{10,11,21,22}$ They also exist in human intercostal muscle. 19.20 .24

From the Neurologische Klinik and Poliklinik dor Technischen Universität München. West Germany (Drs. Kwieciński and Lehmann-Horn), and the Abteilung für Allgemeine Physiologie der Universität Ulm. West Germany (Dr. Rüdel).

Received for publication August 26, 1983; revised manuscript accepted for publication February 9, 1984.

Acknowledgments: The work was performed while Dr. Kwieciński was absent on leave from the Department of Neurology. Medical School, Warsaw, Poland, as a visiting fellow of the Alexander von HumboldtStiftung. Special appreciation is extended to Professor J. Dudel, Institute of Physiology of the Technical University of Munich, for providing labora. tory space in his department. The authors acknowledge with thanks the generous support of Professors I. Hausmanowa-Petrusewicz and A. Struppler. We are grateful to Drs. Mack and Prâuer for the excellent muscle specimens, to Ms. E. Höhne for technical assistance, and to Dr. H. Lorkovic for comments on the manuscript. This work was supported by the Deutsche Forschungsgemeinschatt (Le 481/1).

Address reprint requests to $\mathrm{Dr}$. Rüdel at the Abteilung für Allgemeine Physiologie der Universität Ulm, Oberer Eselsberg, D-7900 Ulm, West Germany.

0148-693×/0706/0465 \$04.00/0

- 1984 John Wiley \& Sons, Inc.
The rectifier properties have been ascribed to the channels conducting potassium ions through the membrane. ${ }^{2}$ It is therefore of general interest to study the dependence of the membrane currents on the extracellular potassium concentration. Moreover, the extracellular potassium concentration rises physiologically to $8-9 \mathrm{mM}$ in the vicinity of skeletal muscles stimulated at a rate of $50 \mathrm{H} /$ for 20 seconds, ${ }^{13}$ changing the ionic conductances. In human skeletal muscle, such studies are of special interest because in familial and symptomatic hyper- and hypokalemic periodic paralysis the paralytic attacks are associated with variations of the plasma potassium content. The reaction of diseased muscle to changes of the plasma potassium can only be understood on the basis of detailed knowledge of the properties of healthy muscle fibers under the corresponding conditions.

\section{MATERIALS AND METHODS}

The experiments were performed in conjunction with the earlier reported study of the resting membrane parameters of human intercostal muscle, ${ }^{17}$ using the same biopsy material. A preparation was placed in a 6-ml Lucite experimental chamber which was continuously perfused with gassed bathing fluid at a rate of $3 \mathrm{ml} / \mathrm{minute}$. When the preparation had been equilibrated in one of the various solutions for at least 5 minutes, the membrane currents were recorded under voltage clamp condi- 
tions. The 3-microelectrode voltage clamping procedure, based on the method of Adrian and Marshall, ${ }^{7}$ was identical to that described previously, ${ }^{19}$ except for the fact that in the present study the steps were prolonged to $60 \mathrm{msec}$ and sometimes covered a wider potential range. A desk computer was programmed with the algorithm of Adrian and Marshall $^{7}$ to calculate the membrane current density at the end of the voltage clamp step as a function of the step size. The current densityvoltage relationships from several fibers (n) of different donors were pooled. The mean values so obtained are presented in Figs. 1-4.

Bretag synthetic interstitial fluid ${ }^{9}$ was used as standard solution. It contained (in $\mathrm{m} M$ ): $\mathrm{NaCl}$ 107.7, $\mathrm{KCl} 3.48, \mathrm{CaCl}_{2} \quad 1.53, \mathrm{MgSO}_{4} \quad 0.69$, $\mathrm{NaHCO}_{3} 26.2, \mathrm{NaH}_{2} \mathrm{PO}_{4}$ 1.67, Na gluconate 9.64, glucose 5.5, and sucrose 7.6. The $\mathrm{pH}$ was kept at 7.4 by gassing the solution with a mixture of $95 \%$ $\mathrm{O}_{2}$ and $5 \% \mathrm{CO}_{2}$. The temperature was set at $37^{\circ} \mathrm{C}$. Solutions having 1 and $7 \mathrm{mM}$ of potassium were made up by altering the $\mathrm{KCl}$ content without correction of the resulting osmotic changes. Solutions having 20 and $60 \mathrm{mM}$ of potassium were made by keeping the sum of the extracellular sodium and potassium concentrations constant at $148.69 \mathrm{~m} M$. A $\mathrm{Na}^{+}$-free solution was made by replacing sodium with Tris (tris(hydroxymethylamino) methane). To obtain a $\mathrm{Cl}^{-}$-free solution, $\mathrm{NaCl}$ and $\mathrm{KCl}$ were replaced by the respective methane sulphonate salts, and $\mathrm{CaCl}_{2}$ was replaced by $\mathrm{Ca}$ gluconate. Tetrodotoxin (TTX, Roth, Karlsruhe, West Germany), 0.3-0.9 mg/liter, and dantrolene sodium (Norwich Pharmacal Company, Norwich, $\mathrm{NY}), 4 \mathrm{mg} / \mathrm{liter}$, were added to the bathing solutions in experiments involving clamp steps to membrane potentials positive to $-60 \mathrm{mV}$ to avoid contraction.

\section{RESULTS}

The current density-voltage relationships (membrane characteristics) determined in TTX-containing solutions with potassium contents of $\mathrm{K}_{\mathrm{e}}=$ $\mathrm{l} \mathrm{m} M$ (filled circles, mean of $n=38$ experiments), $\mathrm{K}_{\mathrm{e}}=3.5 \mathrm{mM}$ (filled squares, $n=112$ ), and $\mathrm{K}_{\mathrm{e}}=7$ $\mathrm{m} M$ (open squares, $n=46$ ) are illustrated in Fig. 1 . A rather high concentration of TTX $(0.9 \mathrm{mg} / \mathrm{liter})$ was found necessary for a quantitative block of the sodium current. Thus, human muscle is about as insensitive to TTX as rat skeletal muscle. ${ }^{7}$ The steady-state current amplitudes were found to be independent of the presence of TTX. In large hyperpolarizing and depolarizing steps, the clamp currents reached a maximum and then slowly de-

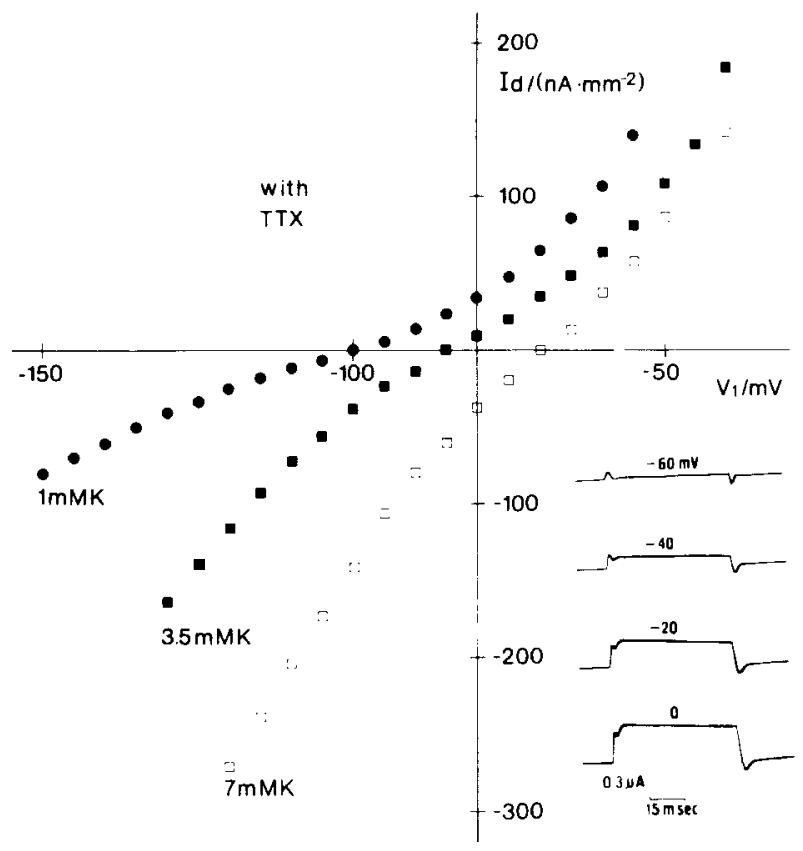

FIGURE 1. Mean steady-state current density-membrane potential relationships (membrane characteristics) of human intercostal muscle fibers bathed in TTX-containing solutions containing $1 \mathrm{~m} M$ potassium (filled circles, $n=38$ ), $3.5 \mathrm{mM}$ potassium (filled squares, $n=112$ ), and $7 \mathrm{mM}$ potassium (open squares, $n=46$ ). The inset shows original traces of currents recorded in a TTX-and dantrolene-containing solution during depolarizing pulses going from the holding potential of $-80 \mathrm{mV}$ to the potential values indicated at each trace (in the presence of $3.5 \mathrm{mM}$ potassium).

clined without attaining a constant amplitude ${ }^{8}$ (see inset to Fig. 1). Preliminary tests showed that the currents at the end of 60 -msec clamp pulses differed by less than $5 \%$ from those at the end of 180msec pulses. To keep the impaled fibers in good condition, we limited the pulse duration to 60 msec. The dependence of the resting membrane potential and of the resting conductance on $\mathrm{K}_{\mathrm{e}}$ as seen in Fig. 1 has been discussed elsewhere. ${ }^{17}$

Inward-Going Rectification. The membrane characteristics showed the typical curvature towards the negative current axis called inward-going rectification (see Fig. 1). This rectification is in the opposite direction to that predicted by the constant field theory. ${ }^{14}$ It is therefore often called anomalous. It is considered to be a property of the potassium channels in the membrane of the transverse tubular system. ${ }^{2}$ In agreement with this assumption, the inward-going rectification was more pronounced when the bathing solution had twice the normal potassium content, and was nearly absent when the potassium content was reduced to $1 \mathrm{~m} M$. 
(a)

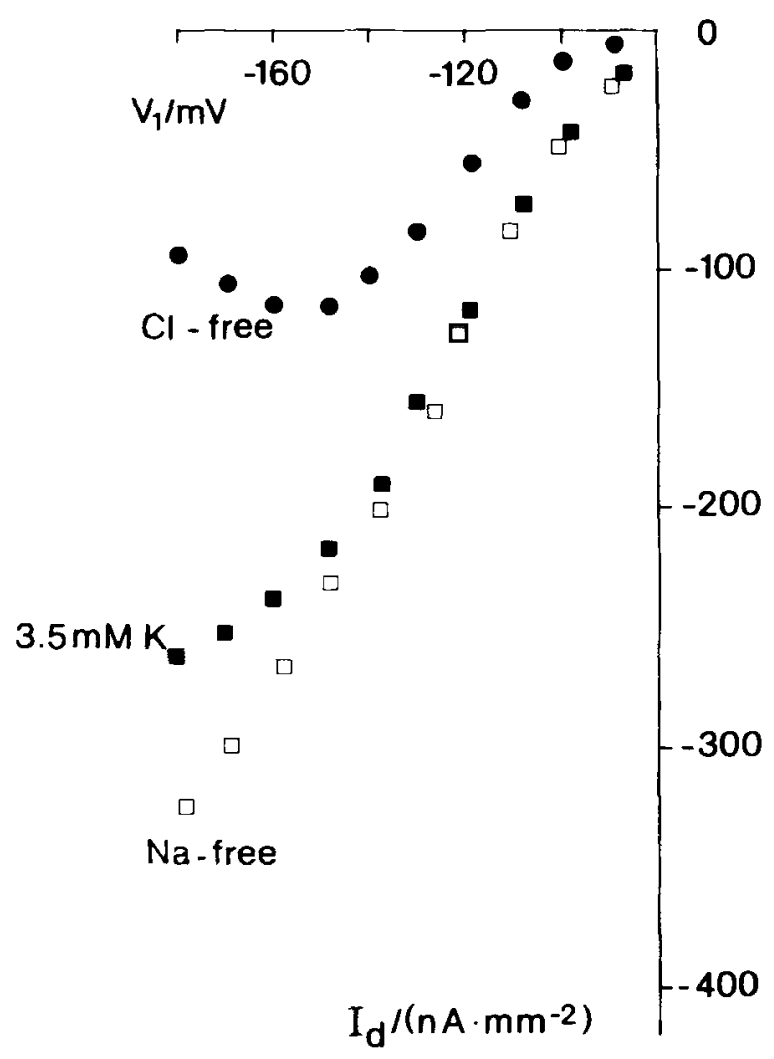

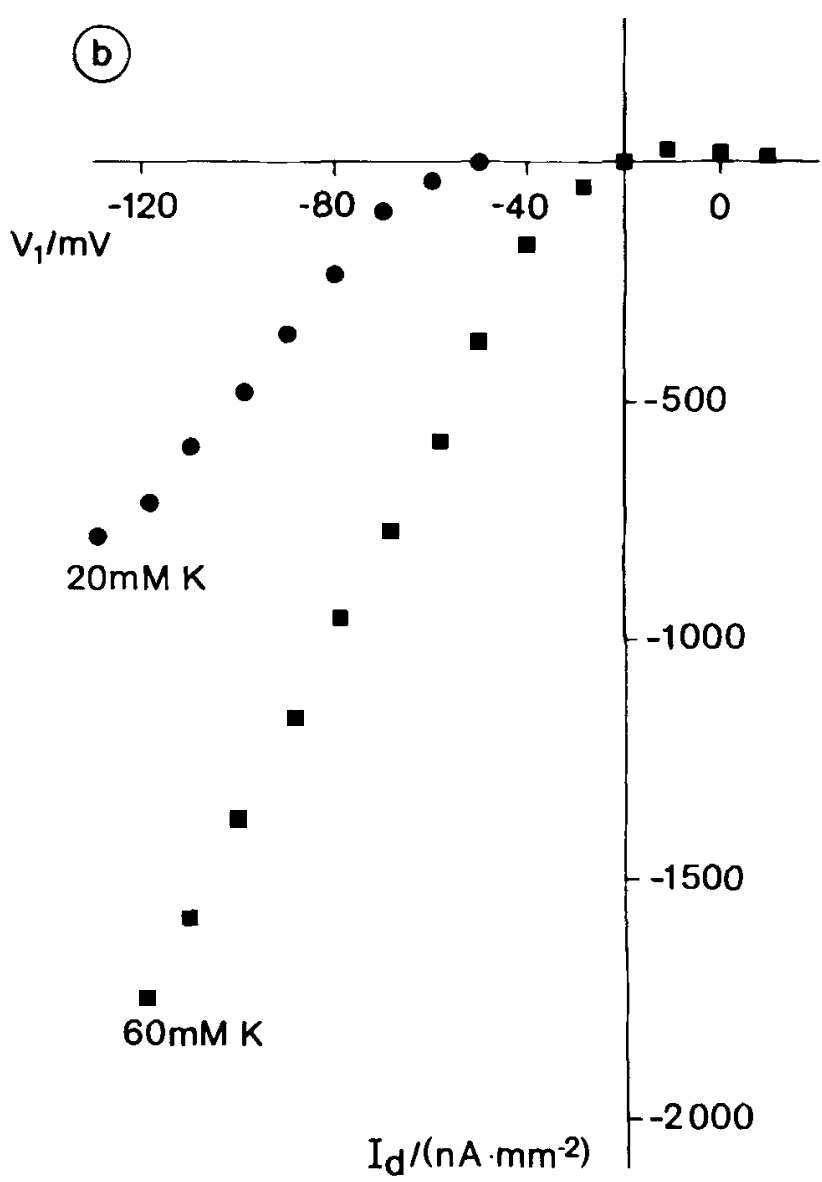

FIGURE 2. Investigation of the inward-going rectification of human intercostal muscle fiber membrane. (a) The means of characteristic curves recorded in a normal extracellular medium (Bretag solution containing $3.5 \mathrm{mM}$ potassium, filled squares, $n$ $=26$ ), in a solution with chloride replaced by methane sulphonate (filled circles, $n=21$ ), and in a solution with sodium replaced by Tris (open squares, $n=5$ ). (b) The means of membrane characteristics recorded in $\mathrm{Cl}^{-}$-free solutions containing $20 \mathrm{mM}$ potassium (circles, $n=10$ ) and $60 \mathrm{mM}$ potassium (squares, $n=12$ ). Note the different scales in the ordinates.

In the standard solution, inward-going rectification was observed between -75 and $-140 \mathrm{mV}$. Between -140 and $-180 \mathrm{mV}$, the increase in membrane current with hyperpolarization was less than proportional (filled squares in Fig. 2a, $n=$ 26). The inward-going rectifier property of the membrane became more pronounced in the absence of extracellular chloride. (Also, the slow decline of the clamp currents mentioned before was more marked in the absence than in the presence of extracellular chloride.) A plot of the amplitudes of the potassium current (filled circles in Fig. 2a, $n$ $=21)$ confirmed that inward-going rectification was present only up to $-140 \mathrm{mV}$. On further hyperpolarization, the potassium current decreased so that the slope of the current-voltage relationship became negative. In frog muscle fibers, Standen and Stanfield ${ }^{25}$ have shown that a potentialdependent block of the potassium channels by sodium ions accounts for the decrease of the mem- brane conductance. To test whether such a block is operative in human muscle fibers, we recorded hyperpolarizing clamp currents in five fibers that were bathed in a $\mathrm{Na}^{+}$-free $\left(\mathrm{Cl}^{-}\right.$-containing) solution. In the potential range from -140 to -180 $\mathrm{mV}$, the membrane currents were significantly larger in the absence of extracellular sodium than in its presence, supporting the idea of a potentialdependent block caused by sodium ions. The results are illustrated in Fig. 2 (open squares).

It is known from experiments with frog skeletal muscle that the current flowing during hyperpolarization is larger as the extracellular potassium concentration becomes higher. ${ }^{6,12,18}$ This was also the case in human intercostal muscle: Fig. 2b shows the current-voltage relationships obtained in solutions containing $20 \mathrm{mM}$ of potassium (filled circles, $n=10$ ) and $60 \mathrm{mM}$ of potassium (filled squares, $n$ $=12$ ). In both solutions, chloride had been replaced by methane sulphonate. In comparing the 


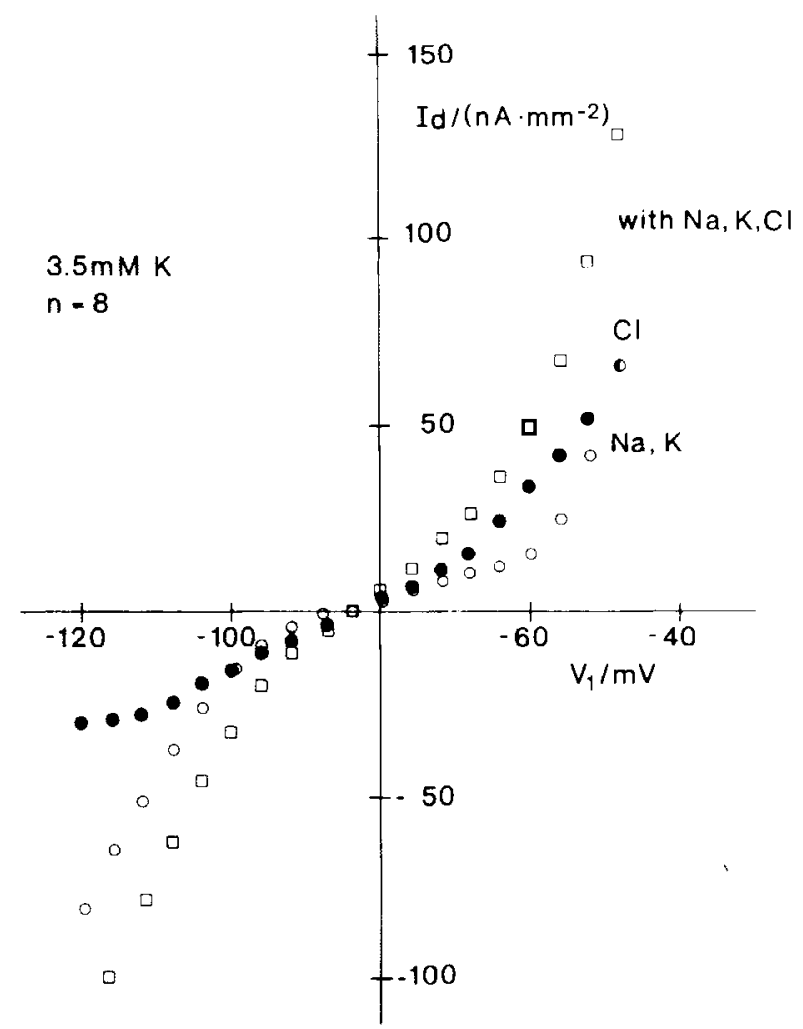

FIGURE 3. Means of characteristic curves recorded in human intercostal muscle fibers bathed in (TTX-containing) solutions with (open squares, $n=8$ ) and without (open circles, $n$ $=8$ ) chloride. The filled circles indicate the difference between currents measured in the presence and absence of extracellular chloride, i.e., the characteristic curve of the chloride current.

current amplitudes in Figs. 2a and b, note the change of the ordinate scale to truly assess the large increase of the inward current with increasing $\mathrm{K}_{\mathrm{e}}$. Inward-going rectification occurred in the range $\pm 20 \mathrm{mV}$ around the resting potential. At large hyperpolarization the membrane characteristics were linear.

Chloride Component of the Membrane Current. The difference between currents measured in the presence and absence of extracellular chloride can be interpreted as the amount of current carried by chloride. This difference is illustrated in Fig. 3 for the condition of normal extracellular potassium concentration $(n=8)$. The filled circles indicate the dependence of the so defined chloride current on the membrane potential. This relationship follows the predictions of the constant field theory. ${ }^{\text {II }}$ In the range from the resting potential to the threshold of the activation of the delayed outward current, chloride current is a major component of the total membrane current.

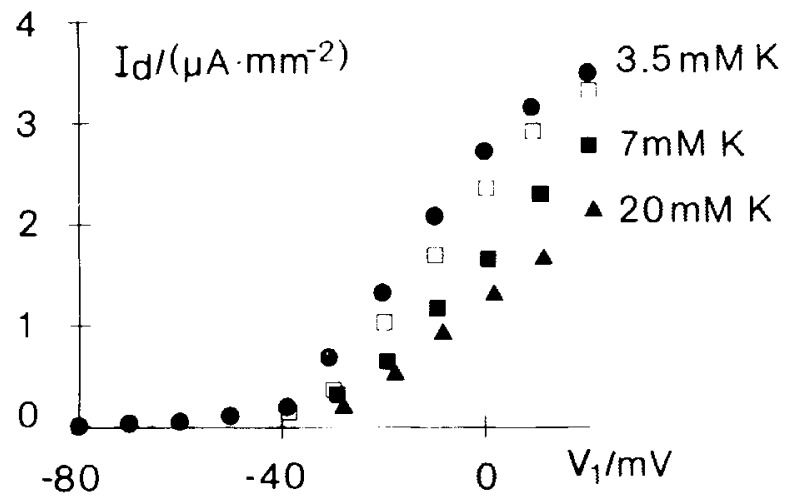

FIGURE 4. Mean steady-state amplitudes of the delayed outward current of human intercostal muscle fibers bathed in solutions containing $3.5 \mathrm{mM}$ potassium (filled circles, $n=$ 22). $7 \mathrm{mM}$ potassium (filled squares, $n=12$ ), and $20 \mathrm{mM}$ potassium (filled triangles, $n=8$ ). The currents recorded in a Cl-free solution containing $3.5 \mathrm{mM}$ potassium are illustrated by open squares $(n=5)$.

Delayed Outward Current. During voltage clamp steps positive to $-50 \mathrm{mV}$ an outward current component was activated with a delay (see original current traces in Fig. 1). The steady-state amplitude of the outward current increased more than proportionally with increasing depolarization (outwardgoing rectification). At positive membrane potentials the outward currents seemed to approach saturation. The steady-state amplitudes of the delayed outward currents decreased with increasing $\mathrm{K}_{\mathrm{e}}$ (Fig. 4).

The ionic components of the delayed outward current were investigated in five experiments by recording the current-voltage relationships in $\mathrm{Cl}^{-}$-free solution. No significant difference wats found between outward currents flowing in the presence and absence of chloride (open squares in Fig. 4), suggesting that the delayed outward current is carried by potassium ions. Replacement of sodium by Tris did not alter the delayed outward currents (five experiments, not illustrated).

\section{DISCUSSION}

The results of this study represent the first comprehensive description of the steady-state membrane currents of human skeletal muscle. The human muscle fiber membrane possesses rectifier properties similar to those reported for amphib$\operatorname{ian}^{1.5}$ and other mammalian skeletal muscles. ${ }^{10,11,21,22}$ Also, the dependence of these rectifier properties on the extracellular potassium concentration resembles the one found in the other animal species. ${ }^{(j, 11}$ Our results allow the same conclusion as the one that has been reached before, namely that these rectifier properties are mediated 
by channels conducting potassium ions. ${ }^{3}$ Although inward-going rectification received much attention in the past, its mechanism and its physiological role are not clearly understood. ${ }^{15}$ The decrease of delayed outward currents with increasing $\mathrm{K}_{e}$ probably represents an increasing slow inactivation caused by the associated depolarization.

In the region around the resting potential, the chloride conductance is the largest component contributing to the total membrane conductance, ${ }^{17}$ and the importance of the chloride conductance for the stability of the resting potential has been well established by the study of myotonic muscle." During depolarization, this contribution becomes relatively less important because of the activation of the delayed potassium current. During hyperpolarization, the chloride current is of the same order of magnitude as the potassium current flowing through the inward-going rectifier channel, and its voltage dependence is not far from linear, in agreement with similar findings obtained in rat diaphragm ${ }^{23}$ and in frog sartorius muscle. ${ }^{16}$

\section{REFERENCES}

1. Adrian RH: 'T he rubidium and potassium permeabilities of frog muscle membrane, $J$ Physiol (Lond) 175:134-159, 1964.

2. Adrian RH: Rectification in nuscle membrane. Prog Biophys Mol Biol 19:339-369, 1969.

3. Adrian RH, Bryant $\mathrm{SH}$ : On the repetitive discharge in myotonic muscle fibres. J Phyiol (Lond) 240:505-515, 1974.

4. Adrian RH, Chandler WK, Hodgkin AL: Voltage clamp experiments in striated muscle fibres. $J$ Phisiol (Lond) 208:607-644, 1970

5. Adrian RH, Chandler WK, Hodgkin AL: Slow changes in potassium permeability in skeletal muscle. $J$ Physiol (Lond) $208: 645-668,1970$.

6. Adrian RH, Freygang WH: The potassium and chloride conductance of frog muscle membrane. $J$ Physiol (Lond) $163: 61-103,1962$

7. Adrian RH, Marshall MW: Sodium currents in mammalian nuscle $J$ Physiol (Lond) 268:223-250, 1977.

8. Almers $W$ : The dedine of potassium permeability during extreme hyperpolarization in frog skeletal muscle. J Physiol (Lond) 225:57-83, 1972

9. Bretag AC: Synthetic interstitial fluid for isolated mammalian tissue. Life Sci 8:319-329, 1969.

10. Duval A, Léoty $C:$ : Ionic currents in mammalian fast skeletal muscle. J Physiul (Lond) 278:403-423, 1978.

11. Duval A, Léoty $C$ : Comparison between the delayed outward current in slow and fast twitch skeletal muscle in the rat. J Plowstel (Lond) 307:43-57, 1980.

12. Ilestrin $S:$ The interaction of potassium with the activation of anamalous rectification in frog muscle membrane. $J$ Physiol (Lond) 317:497-508, 1981.

13. Hnik P, Holas M, Krekule I, Kriz N. Mejsnar J, Smiesko V, Ujec E, Vyskocil F: Work-induced potassium changes in skeletal muscle and effluent venous blood assessed by liquid ion-exchanger microelectrodes. Pfluegers Arch 362:85-94, 1976

14. Hodgkin AL, Katz $\mathrm{B}$ : The effect of sodium ions on the electrical activity of the giant axon of the squid. $J$ Physiol (Lond) 108:37-77, 1949.
15. Hutter OF: Going through the usual channels, in Varga $\mathrm{E}$, Kover E, Kovacs T, Kovacs L (eds): Advances in Physiological Sciences, Vol 5. New York, Pergamon Press, 1980, pp 227238.

16. Hutter $\mathrm{OF}$, Warner $\mathrm{A}$ : The voliage dependence of the chloride conductance of frog muscle. J $P / h^{3}$ is (lomd) 227:275-290, 1972.

17. Kwieciński H, Lehmann-Horn $R$, Rüdel $R$ : The restings membrane parameters of human intercostal muscle at low: normal, and high extracellular potassium. Muscle Norte $7: 60-65,1984$

18. Leech CA, Stanfield PR: Inward recification in frog skeletal muscle fibers and its dependence on membrant potential and external potassium. I Physot (Lomu) 319:29:-3099. 1981 .

19. Lehmann-Horn F, Rüdel R, Dengler R, Lorković H, Haass A, Ricker K: Membrane defects in paramyotonia congenita with and without myotonia in a warm environment. Murle Nerce 4:396-406, 1981 .

20. Lehmann-Horn F. Rüdel R. Ricker K. Lorković II, Dengler R, Hopf HC: Two cases of adynamia episodica hereditaria: in vitro investigation of muscle cell membrane and contraction parameters. Muscle Nerve 6:113-121, 1983.

21. Lorković $\mathbf{H}$ : Voltage-current relationships in skeletal muscles of rats. Arch Physiol Biochim 84:925-938, 1976.

22. Lorković $\mathrm{H}$ : Effect of sodium on the voltage-current relationships in rat muscles. Arch Physiol Binchim 84:939-9.54. 1976.

23. Palade PT, Barchi RL: Characteristics of the chloride conductance in nuscle fibers of the rat diaphragm. I Gen Physiol 69:325-342, 1977.

24. Rüdel R, Lehmann-Horn F, Ricker K, Küther G: Hypokidlemic periodic paralysis: in vitro investigation of muscle fiber membrane parameters. Muscle Nerve 7:110-120, 1984.

25. Standen NB, Stanfield PR: Porassium depletion and sodium block of potassium curtents under hyperpolarizdtion in frog sartorius muscle. J Phywiol (Lond) 294:497-520, 1979. 